Article

\title{
Assistive Technologies: Social Barriers and Socio-Technical Pathways
}

\author{
Linda Nierling * and Maria Maia \\ Institute for Technology Assessment and Systems Analysis (ITAS), Karlsruhe Institute of Technology (KIT), \\ 76131 Karlsruhe, Germany; maria.maia@kit.edu \\ * Correspondence: linda.nierling@kit.edu
}

Received: 8 January 2020; Accepted: 25 May 2020; Published: 31 May 2020

check for updates

\begin{abstract}
Against the background of recent international regulation, the role of assistive technologies in the fields of independent living, education, and employment is analyzed in this article to propose a future strategy for a socio-technical perspective on their further development processes. Based on qualitative expert interviews at the European level, the role and scope of ATs in these fields are described for three types of disabilities: visual impairment, hearing impairment, and autism spectrum disorder. The findings show that digitalization processes entail major opportunities and challenges for ATs in all three fields and that further measures are needed to bring technical opportunities to their full potential in adverse social contexts. Regarding future technology development, the authors propose a development strategy focusing strongly on the social context of the devices. Only in this manner, relevant "unintended consequences", as well as social or ethical concerns, can be identified and addressed.
\end{abstract}

Keywords: assistive technologies; disability; independent living; employment; education; socio-technical system; responsible research and innovation; technology assessment

\section{Introduction}

The lives of people with disabilities can be influenced by technologies in various ways. A large variety of such technologies fall under the header of "assistive technologies" (ATs). These technologies can be highly specialized, depending on the type of disability they are aimed at and whether they were developed as medical technology with a specific focus or as so-called mainstream technology, which just happens to serve the needs of people with disabilities, too. Recent trends of digitalization also brought about new applications and technological developments that were also relevant for people with disabilities. Assistive technologies experienced a further massive boost at the international level with the United Nations Convention on the Rights of Persons with Disability (UNCRPD).

The Convention was a major step to foster the social understanding of disabilities by focusing on the existing barriers at the social level, but also to promote ATs as a medium to advance the inclusion of people with disabilities into different fields of society such as everyday life, education, and the labor market ${ }^{1}$.

The main idea is that ATs provide people with disabilities with technical support to overcome social barriers too. Spinning off from the Convention, further activities have been started at both the international and the European level, such as the Global Cooperation on Assistive Health Technology initiative (GATE) or the European Accessibility Act (EAA).

1 In the UNCRPD, ATs are promoted in nine articles. 
The definition of "what is a disability" has been contested in the community for a long time.

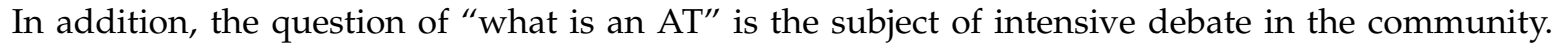
The concept of ATs, following the ISO 9999:2017-03 standard, classifies them in a formal and narrow way, also paving the way for medical reimbursement (e.g., hearing aids). However, there is also an alternative understanding of ATs put forward, which does not frame them as medical, but rather as mainstream technologies that can be used by people in need of support, regardless of existing (or the lack of) disabilities (e.g., the use of voice guidance in a navigation system).

Probably the most accepted definition of ATs is the one provided by the World Health Organization (WHO), where ATs are specified as products, systems, and services which "maintain or improve an individual's functioning and independence and thereby promote their well-being" (see [1], p. 1). A look at AT inventories such as the European Assistive Technology Information Network (EASTIN), a web-based data platform with more than 70,000 AT products worldwide ${ }^{2}$, quickly reveals a vastness of technical solutions for different types of disabilities. Some examples of ATs are haptic or tactile aids for the blind or visually impaired, such as the white cane or braille systems, as well as apps, software and hardware, or devices of daily use (e.g., washing machines) equipped with a speech interface to support them in their daily activities. For people who are deaf or hearing-impaired, technical support focuses on either increasing the sound or replacing it with other communication modes. This includes hearing technologies (such as hearing aids or cochlear implants), alerting devices with light or vibration, communication technologies, or apps based on texts or video (e.g., WhatsApp or Skype). For people with autism spectrum disorder (ASD), the difficulties in participating in social exchange and communication are the main barrier. Therefore, augmentative and alternative communication technologies, either low-tech (e.g., card symbol system) or high-tech (e.g., communication apps using a symbol system), can be supportive [2].

However, despite the many ATs available, a high proportion of ATs are not accepted by the users (see [3], p. 4). One factor influencing this rejection is related to the lack of an appropriate design.

Therefore there is an urgent need for research and development driven by the needs of the users and the specific context [3]. An interplay between technology and its fields of use is important to ensure that the technology will indeed fulfill the users' needs, meaning that not only requirements of engineering, manufacturing, and ergonomics are considered, but attention is also paid to user experience, the aesthetics of the technology, and the quality of its interaction with the user [4].

Accessibility to essential ATs does not only imply the development of technological innovations that make ATs available and cost-effective. They should also be embedded into a social innovation setting, making sure that they can be adapted to the context in which they are going to be available and, above all, involving developers and users in order to contextualize their adoption to local settings [5]. Innovation in health thus encompasses "the need to create and implement both social and technological solutions" ( see [6], p. 1059).

A socio-technical approach that explicitly embraces the idea that social and technical aspects are interconnected and should be considered equally and jointly designed is therefore important. However, this approach does not come without challenges. Some of these will be addressed in this article.

The article intends to shed light on the current socio-technical challenges of ATs. It will present empirical results from a study for the European Parliament (2016-2017) which did not only aim to identify the needs and opportunities related to ATs from a user perspective, but also looked for complementary measures by the public sector [7]. The study focused on three different disabilities (blindness and visual impairment, deafness and hearing impairment, and ASD). It revealed that despite the high rate of use and openness toward ATs, there are still various social barriers that are considered to be relevant for hindering/enabling the integration of people with disabilities into social contexts [7].

2 The EASTIN brochure “The Global Assistive Technology Information Network” is available at http://www.eastin.eu/en-gb/ GeneralInfo/List (accessed 21 December 2019). 
Based on expert interviews conducted at the European level (Section 2), we will explore the main social barriers people with disabilities have to face and the role ATs can play in this respect (Section 3). These empirical results will be followed by a discussion of a socio-technical approach that challenges the current strategies of AT development also with regard to further conceptual approaches like Technology Assessment (TA) and Responsible Research and Innovation (RRI) (Section 4). Conclusions will then be drawn (Section 5).

\section{Methods}

In this article, we refer to two sets of semi-structured qualitative interviews conducted at the European level (for guidelines see Appendix A) with experts in the field of ATs and people with disabilities. The first set of interviews was dedicated to the needs and perceptions of disabled people from all three groups regarding ATs. It focused on practical experience, specific needs in relevant societal fields, perceptions and attitudes toward ATs, and present and future challenges. Experts from European disability organizations (European Union of the Deaf (EUD), European Union of the Blind (EUB), and Autism-Europe (AE)) as well as pan-European user groups (e.g., European Association of Service Providers for Persons with Disabilities (EASPD)) were interviewed. The second set of interviews focused on complementary measures by the public sector to improve the inclusion of people with disabilities. It encompassed both the experience with political measures concerning ATs and opinions on further political measures following the UNCPRD and addressed current and future political developments. The interviewees included representatives from relevant stakeholder groups, namely, in addition to the ones mentioned above, European disability organizations, experts from medicine, research, industry, the WHO, and the International Labour Organization (ILO) (cf. Appendix B for the list of interviewees).

Most of the interviews took place as video conferences between May and August 2016, lasted approximately $60 \mathrm{~min}$, and were recorded and transcribed. Two interviews were conducted via email due to language barriers since the interviewers were not familiar with sign language and had no resources for a sign language interpreter. The written content of the interviews was coded along the main categories of the interview guidelines, following the rules of qualitative content analysis [8] with software support (MAXQDA Version 11$)^{3}$. The direct quotes provided in the paper follow the transcription reference: the organization of the expert (e.g., EBU) and the line of the transcription (e.g., 10). The analytical strategy for the classification and interpretation of the qualitative data was oriented by subcategories. The subcategories were developed from the guiding research foci of the two sets (see Appendix C). Set 1 was dedicated to the perceptions and needs of people with disabilities related to ATs. Set 2 focused on political measures. In both sets, the role of ATs in different societal fields was covered. In this article, we draw on the results of the two sets in order to present current perceptions and needs with regard to ATs raised by people with disabilities and potential political measures to address these.

The results presented in this paper are based on the project report by Nierling et al. (2018). However, in this paper, we go one step further regarding the data analysis and results presented, as well as the reflections and conclusions made.

\section{Empirical Results: Disabled People's Perceptions and Needs of ATs and Related Political Measures}

The interviews revealed that people with disabilities from all three groups agreed that ATs are important support in the activities of their daily lives. From the perspective of European disability organizations, an AT can "help people with their disabilities to overcome their impairments, from our society and interaction with society" (AE 1, 16). Hereby, ATs are regarded as an "interface" (EBU 1, 14) used

3 VERBI GmbH, Berlin, Germany. 
to "improve the personal capacity in a given environment and task" (EUD 1, 17). The main idea is that even if the "environment is disabling" (EUD 1,48), ATs can be a support to enter and access this environment. The achievement of "independence" (EBU 1,44), either in performing tasks on a daily basis or being integrated into education or employment, is seen as an important factor for full inclusion and participation in society.

The reach of ATs is not as clear as it appears at first glance. Although a multitude of opportunities emerges with the use of ATs promoting the inclusion of people with disabilities, a closer look at the three mentioned fields_-independent living, education, employment-reveals that ATs can only offer support to overcome some of the social barriers, but not all of them. Thus, a socio-technical perspective is crucial for exploiting their full potential. This concerns the design, development, and implementation process as well as the successful use of ATs in their different social contexts. In the following, the role and use of ATs for special types of disabilities are also presented in light of potential political measures.

\subsection{Independent Living}

Independent living is understood as the ability to lead one's own life. For people with disabilities, this can imply the need to rely on ATs. Blind people experience this need, especially in relation to the accessibility of everyday technologies. This includes not only "tangible" technologies with an accessible user interface, but also internet applications (e.g., public transport schedules or banking transfer apps). Even though there are several solutions available for support in daily activities, these technologies do not always match the specific user's needs if they lack their full functionality. A braille display not showing a full graph or chart, automated teller machines (ATMs) that are accessible only through touchscreens, or TV sets without voice commands are some of the examples given by one expert in the interview (EBU 2, 31). The importance of access to such everyday technologies for the visually impaired has to be voiced again and again.

Access to the virtual world represents another main challenge for this group, some sort of social integration that is almost expected nowadays. Visually impaired do not only encounter barriers connected to public e-services such as banking or e-governance (EBU 2, 92) but also to social media that are mainly based on pictures, e.g., Instagram, Facebook, Tweeter, and Flickr. Such platforms still lack the tools to fully achieve the "virtual integration" of the blind.

However, some steps were taken in this direction. Facebook, for instance, developed software to describe images and pictures: "They developed artificial intelligence software to check what's on the picture and to speak it so again" (EBU 1,83). However, there is still a gap; not all virtual platforms are accessible to all their users.

In the case of ASD, the barriers for fully independent living can be mainly found in the field of communication. Here, technologies can play a vital role by acting as a channel for communication. Digital devices are important as they can substitute verbal communication with non-verbal cues, e.g., replacing words by symbols or translating symbols into voice: "You can see people with autism without verbal language, with intellectual disabilities, able to use tablets and smartphones very easily. They are very comfortable with technologies in spite of being intellectually disabled because to touch, to use images, to use symbols, ... it is adapted to our cognitive style" (AE 1,77). Although there are positive experiences with such technologies, people with ASD still face several barriers in daily communication. In addition, despite the manifold technical opportunities available, they are not always well known. For instance, in public services, there is often a lack of knowledge, on the one hand on how to address a person with ASD, and on the other hand regarding the tools available to promote communication: "Because in public services we need to go in a public space, to look for information. It's difficult for us to ask people... and ... so it could be trained staff to help it, would be useful." (AE 1,123). This applies to several areas of public services, such as health, education, civil services, and police forces. The experts interviewed provided two examples: In the field of health care, the disability often prevents a doctor from making the right diagnosis for people with ASD (AE 2,54-56). This also applies to the police: “We see sometimes reports in the media of people getting shot because they were displaying challenging behaviours. But the thing 
is that they had autism, it was not they were being confrontational with the police on purpose. It's just their disabilities, that they don't always understand social norms, social communication. And they can at times be very, very stressed and react in an unusual way to some situation" (AE 2, 81). So ATs can also play an important role in this context: to improve communicative abilities and exchange. Technologies, as such, cannot resolve communications issues; thus, not only a better understanding of the specificities of the disability is required but also adequate training and widespread knowledge of the availability of tools that support and foster communication.

Following the publication of the EAA in early June 2019, we can expect improved access to everyday technologies for people with disabilities, due to new technological solutions in the field of independent living. The EAA creates an obligation for the Member States to ensure that the same products and services (for instance, computers and operating systems, ATMs, ticketing and check-in machines, telephones and smartphones) are placed in the market, complying with accessibility requirements [9].

\subsection{Education}

Especially in the field of education, the use of ATs has a long tradition [10]. ATs have been used to integrate students with disabilities into the regular educational system for many years. From the perspective of people with disabilities, there is a great openness toward these developments, as they allow them access to better educational opportunities, for instance, for the visually impaired, as expressed by an expert: "So it helps integrating in normal education indeed: Before we had assistive technologies, we had schools for the blind" (EBU 1,50). However, devices are very specific and have to be developed, applied, and implemented according to the type of disability. In addition, progress with access to information on the internet is emphasized, which is a big advantage for the blind or visually impaired. Access to online courses or e-learning platforms is a very important step for them. Here, on a practical level, mainstream technologies can be supportive, as long as the educating organizations and teachers provide material on platforms that are accessible (EBU 1, 50; ILUNION, 50). Overall, access to knowledge via the internet improved the situation for people with visual impairments a lot. One expert states: "I'm extremely happy with something like the internet because it's my accessible library, which 20 years ago, if you would have looked up something, I would have had to ask somebody to come with me to a special building with information, now I can do it independently, as long as the websites are accessible" (EBU 1,36). For pupils with ASD, the spectrum of needs related to technology is again very broad. Children with ASD who are not able to communicate with verbal language can use an assistive device to point to pictures or symbols instead (AE 1,43). Therefore, tablets with specific apps are a central and important device for pupils with ASD in school.

Beyond the concrete process of education in different institutions (schools, universities), several experts stressed the special importance of education for people with disabilities to overcome barriers at a technical or social level. With a profound education, people with visual impairments do not have to rely on special devices, but can make their own choices and use mainstream devices: "I believe it's much more efficient for people to have a good education and where they can learn how to use all the goods from the available technologies, which is becoming something that's mainstream" (EBU 2, 120). Furthermore, the experts emphasized that the level of education is also crucial for the use of technologies to lead an independent life since a good educational background provides an important basis for independent use of mainstream devices. In the case of ASD, the role of education is considered equally crucial in a comprehensive sense: "education for people with autism, that is more than mere education, it will help to really understand the world better" (AE 2,54). This understanding of "the world" also becomes very relevant regarding ATs. Especially the use of new digital technologies such as apps involves complex decisions and knowledge, e.g., data protection, sensitive personal information, where decisions are mainly made at the individual level as regulative instruments are still not in place.

Interestingly, the experts interviewed not only stressed the role of ATs in the education process of people with disabilities, but they also mentioned that important barriers to web accessibility result 
from a lack of training in ATs by professionals working for and with people with disabilities. This lack of training is identified in two different areas. First, there is a serious lack of professionals for web accessibility. According to one of the experts, recent official reports state that "90\% of European web and app developers lack the skills (... ) to develop effective interfacing for people with disabilities" (University of Sheffield, 23). One important aspect contributing to this is the nonexistence of certificates in Europe proving qualifications and skills and providing incentives to learn about web accessibility. The proof of expertise in this field relies on certification programs already existing in the US (EBU 2, 56). Second, there is a lack of training in occupational profiles in the health care sector. In many health and care professions, technologies are not integrated into the "expertise or requirement in their training" (University of Sheffield, 47). Often even people actually affected, such as people with disabilities, are "far more open to the use of new technologies as part of the solutions than the practitioners" (University of Sheffield, 49). An expert from the WHO proposed that this lack of skills could be overcome by the introduction of a specialized profession, the Assistive Technology Professional (ATP), already established in the US, where ATs are not prescribed by medical doctors (as in Europe), but by specific occupational groups, e.g., a physical therapist certified as ATP. This model allows knowledge about ATs to be spread out to more occupational health groups.

The results presented show that the integration and use of ATs in their everyday context is crucial for people with disabilities to overcome certain barriers, especially regarding digital devices. However, it must be emphasized that training and qualification concerning ATs and their usage are not only relevant for people with disabilities, but also for IT and health professionals working with people with disabilities.

\subsection{Employment}

A sound educational system is the key to assuring the inclusion of people with disabilities in the labor market. When it comes to employing disabled people, a high level of knowledge and skills, especially on how to use the available technologies to widen one's own knowledge base, is seen as crucial: "The general access to information society (...) has an impact on the employability of people. So the more people have access to technology that allows them to take part in all aspects of life that also has a positive impact on their capacity to be effectively included in the labour market." (ILO, 45).

ATs are of high relevance, not only in the field of education in general but also in the field of employment [10]. Without a doubt, technical solutions in the workplace have the potential to "make the labour market more disability friendly" (EASPD, 33) and show a large variety of useful technological solutions in the fields of disability addressed. While people with visual impairments need access to information and communication technologies and applications such as screen readers or software for voice control, persons who are deaf or hard of hearing benefit from applications such as "sign language interpreter over the net" (EUD 2, 3785). People with ASD can use technology-based training for social interaction in the workplace, which can be delivered, e.g., by augmented reality applied in video games, simulating professional tasks as well as critical simulated social situations at the workplace. Such upfront training of practical settings can support people with ASD: "There is a simulation by a computer to understand the workplace. Like a video game, you can start your day, go to your office, to your laboratory and you say 'Good morning' to your colleagues. You walk to your table, you wait for your boss or you can do your activities and you can simulate your working task. And so you can prepare when you meet your real colleagues in person, because social interaction is really hard" (AE 1,71).

Although there is a range of technical support devices and software available, technologies still play a minor role when it comes to the inclusion of people with disabilities into employment. Major "attitudinal barriers" (ILO, 27) and negative perceptions of relevant societal players like "government, employers, trade unions, (...) media" (ILO, 45) regarding the working capacity of people with disabilities prevent their inclusion. Such "attitudinal barriers" are often already prevalent at the recruitment stage. In order to improve such scenarios, modifications of company procedures on the employer side can support the overcoming of these barriers. For instance, in the case of ASD, the standard job interview 
is already very challenging, but, e.g., a test in a real situation to demonstrate skills would be a way to adapt this procedure to people with ASD (AE 2, 54). Additionally, regarding the working environment, "lots of rather simple and easy accommodations" (AE 2,54) exist, which could include people with ASD in the workplace. As people with ASD are oversensitive to light and sound, an adaption of light or a quiet workspace with little interaction with others would be supportive. Due to the large number of different manifestations of ASD, "a proper individualized approach" (AE 2,52) is necessary, and individual support programs were already successful regarding the inclusion of people with ASD in the labor market. However, their national and regional range is limited.

To improve the situation for people with disabilities in the labor market in general, the experts highlight two aspects. The first one is related to the further development of legislation to strengthen elements already addressed in the UNCRPD. In particular, Article 2 (reasonable accommodation) can serve as a starting point to bring assistive devices into the workplace (ILO, 39). According to the UNCRPD Art. 2: “'Reasonable accommodation' means necessary and appropriate modification and adjustments not imposing a disproportionate or undue burden, where needed in a particular case, to ensure persons with disabilities the enjoyment or exercise on an equal basis with others of all human rights and fundamental freedoms." [11]. However, although the UNCRPD is currently implemented in the legislation of many countries, implying that "the denial of reasonable accommodation is a form of discrimination" (ILO, 39), until now, no "huge changes" (ILO, 39) have taken place. The second one concerns the role of companies. In general, there is a huge lack of knowledge at the companies' side on how to employ people with disabilities. There is an urgent need for a better knowledge base that is easily accessible for companies, providing information on how to employ people with a disability, e.g., on legislative steps, practical adjustments, and funding opportunities (AE 2, 54; ILO, 39). These two measures could also be the first steps to overcome cultural barriers while minimizing the "costs", either financial or in terms of processes which occur in companies (University of Sheffield, 27).

According to the experts, the inclusion of people with disabilities into the labor market represents the most challenging field, where social and cultural barriers remain strong and can only be overcome over time and with great effort. Technological solutions can play a major role in that process.

Overall, every type of disability has its very own characteristics. There is a wide range of technological opportunities to overcome existing barriers for the blind, although the accessibility of these solutions has to be constantly checked. When it comes to the integration into virtual worlds, new developments are still needed. In the case of ASD, however, the situation is very complex due to the specificities of the disability, and the role of technology is to provide support for social integration. The development of technological solutions is also still in its initial state. The disability is characterized by a broad variety of manifestations and was first diagnosed only 30 years ago in most European countries. Today we have the first generation of adults who, in the case of Asperger, also want to represent their own rights. Similar to the deaf and hard of hearing community, they claim that ASD should be recognized as part of human diversity and does not need to be "cured": "they are proud to be autistic and they say it's just part of the diversity of human nature" (AE 2,63). This also refers to the neurodiversity movement [12].Therefore, there are major opportunities for future technology development as people with ASD are very open toward support through technologies.

\section{Discussion: Adequate (Socio-) Technical Developments of ATs}

The previous sections revealed that a reflection on ATs does not focus on the mere technical aspects, but rather on the question of how these devices are integrated into the social settings of people with disabilities. Thus, the role of ATs needs to be considered in the wider societal context of these people. A deeper reflection is necessary: which challenges will we encounter when asking/looking for the further development of ATs? This section deals, on the one hand, with the challenges of AT development and, on the other hand, with the social and ethical concerns raised by such developments.

When technological futures of ATs are addressed, there is often a strong focus on high-tech devices, e.g., in neurosciences (brain-machine interface), augmented reality, or applications such as 
the bionic eye $\mathrm{e}^{4}$. In addition, autonomous driving provides people with visual impairments with many opportunities for free and independent movement and travel. These technologically advanced solutions can provide beneficial options for people with disabilities in the future. However, against the background of our findings, we would like to take another perspective on "technology development". At the general level, the majority of people with disabilities in the interviews were very open to technological solutions. However, needs and expectations associated with ATs can be very specific, regarding both the type of disabilities and the particular context of a person (such as country of residence or age). Our research revealed that there are major differences for people with disabilities depending on national settings [13] and age. Users who become disabled at an older age face much more barriers related to technology use than disabled users who have been familiar with ATs since their childhood.

Irrespective of these differences, it is common that every technology development has to be accompanied by efforts regarding aiming at the social embedding of such technical solutions. Regarding the development process of technologies, there are already many approaches have already been taken underway, like universal design principles, user-centered design ${ }^{5}$, or participatory design, which are applied in all stages of the technological development (see, for instance, [13-15]), so that the decisions that are made ensure that future technologies meet the needs of people with disabilities and are well perceived by them ${ }^{6}$. For long, these ideas have been the core of Technology Assessment (TA) [16] and, more recently, are embraced by the prominent European paradigm of Responsible Research and Innovation (RRI) [17] and are partly addressed in the EAA.

The main motivation behind the efforts in both fields, RRI and TA, is the need to ensure that research and innovation activities are socially acceptable, desirable, and sustainable. Some examples of applications are a user-centered design to ensure the inclusion of the user at all levels of decision making, in a bottom-up approach, promoting a co-design or co-creation between users and industry. This includes cooperative design (where designers and users are involved on an equal footing), participatory design (where users are involved through active and participative processes), and contextual design (where the participatory process occurs in the actual context or environment) [18]. In this sense, a user-driven design approach will ensure that future technologies truly meet the needs of people with disabilities, are well perceived by them, and do not reproduce stereotypes and prejudices. AT users are no longer conceptualized as passive recipients and users of the technology, but, in contrast, they are empowered to participate in each stage of the technology design and development [18].

The possibility to withdraw from the use of technology should be given at all times. In addition, full and accurate information on the risks and benefits of technology use should be provided. In our interviews, this aspect was mentioned several times: "We are actually desperate to have much more information about how best to use technologies that we already have" (University of Sheffield, 41). However, in addition to the design process, there should also be a more explicit focus on the interrelations in the social context an AT is directed to. Thus, the invention of new devices should be accompanied by a stronger focus on existing technical solutions, their actual spread and diffusion, as well as their connection to accompanying services, or, in other words, the life cycle and living environment of an AT should receive more attention. Measures such as an evaluative inventory based on a quality assessment of existing devices or even a sector-wide coverage of specific useful devices in social

4 The bionic eye is an example of a technology development aiming to replace malfunctioning organs. This technology is, however, associated with many challenges. These challenges are not only related to technology development per se, but also to the limitations of the human body and adaptations required to receive a full acceptance and integration of this technology. One example could be the time a child needs to achieve his or her full ability to see (measuring distances, identifying colors, assess moving targets).

5 User-centered design is based on human-centered design principles. It means to start with the with a good understanding of people and the needs that the design is intended to meet.

6 Interestingly, in the case of ASD, we have observed a variety of that there are manifold activities of "bottom-up" activities technical development, where families develop specific technical applications for specific needs. Here, we can witness the rising of a growing do-it-yourself (DIY) movement in the communities. 
services, health care, education, or employment could be the first step. Such evaluation approaches should be coupled with approaches connecting existing useful, often mid-tech devices with related services that would imply, e.g., the continuous training of occupational groups. Simple questions such as "What is already there?" or "How can it be implemented most efficiently?" can make a big difference in the process of a "socio-technical" development perspective on ATs. In times of scarce health care budgets across Europe, such approaches would contribute to ensuring the accessibility but also the affordability of the devices [19].

Looking at the future development of ATs, the connection to approaches like Technology Assessment (TA) or RRI could be made even more explicit as the field of ATs would profit from them, since there are also contradictory values emerging. One example is the progress in IT-based facial recognition. Such technology is welcomed, for instance, by visually impaired, who could take advantage of the immediate description of what or who they encounter, but also by children with ASD who could use applications recognizing facial expressions to support them in school. However, concerns related to privacy issues have been raised with good reason in broader societal debates. Thus, potential benefits for specific groups must be carefully balanced with their drawbacks for other user groups, or even society in general.

In addition, also ethical concerns related to ATs could be addressed under this umbrella. An important question in the context of embodied ATs (such as exoskeletons, cochlear implants, or the bionic eye) could be our understanding of "normality" and how it may be challenged by disabilities and ATs. Is walking the only "adequate" way of moving? Do we need to "hear" to be able to communicate properly? What is "seen" through a bionic eye: reality or modified reality? In what ways do embodied ATs also limit the personal autonomy of people with disabilities?

Furthermore, there is the risk that such embodied high-tech devices substituting bodily "mal-functions" may even lead to social concerns, e.g., that there could be a cut-back of social (human) support since related "problems" are already "fixed" by technology. Thus, it can be more and more difficult for people with disabilities to decide against such technologies as this might imply stigmatization or even exclusion from social life or employment (e.g., ongoing controversy on cochlear implants).

In summary, we can state that the adequate development of the technical aspects of ATs-a topic that has been intensively discussed already in recent years-should not be taken lightly. It is still of vital importance since it also includes the social context of ATs, which cannot be ignored. The "social context" is crucial for exploring the future role of ATs. In the general debate, technical devices are very often classified and regarded as the main tool to overcome barriers. However, they are devices only, and as such, their opportunities to initiate a change in society are limited. Instead, we should rather stress their importance in individual settings since they contribute to increasing the quality of life of individuals, giving them the opportunity to actively participate in social life.

\section{Conclusions}

Many of the problems that people with disabilities have to face in their everyday lives can only partly be attributed to inappropriate ATs. It is rather the circumstances and social environment of people with disabilities that are crucial. Nevertheless, as shown in this article, there are important aspects of ATs for people with disabilities that represent a complex structure with manifold socio-technical connections rather than a single technological solution. In the analysis, we presented our empirical results from three social fields-independent living, education, and employment-where barriers but also political measures were described for people from three groups of disabilities: visual impairment, hearing impairment, and ASD.

When it comes to independent living, the main goal of ATs is to support people with disabilities in leading an autonomous life. However, there are still many barriers. In the case of visual impairment, we could mention the barriers to access to mainstream devices as well as missing links for their equal integration into virtual worlds. In the case of ASD, despite the disabled people's great openness toward 
technical solutions, especially digital ones, the societal barriers are very complex, so that technology itself can only play a minor role here. Thinking further ahead at the upcoming challenges in this field, the ongoing trend toward an individualistic lifestyle presents a major challenge for independent living. Since the traditional role of the family is becoming less and less important, one has to be especially aware that the implementation of ATs could lead to decreasing human support. Furthermore, it has to be avoided that extensive use of technologies leads to social deskilling and emotional isolation. The normative rationale behind the development and implementation of ATs in the field of independent living should be directed toward a joint engagement in daily life, e.g., to overcome mobility barriers for visually impaired, to train and ease social interaction for ASD, or even to transform sounds into images for the deaf or hearing impaired.

The field of education is a "traditional" field where ATs have been applied and used for a long time. ATs are of high relevance here as they allow people with disabilities to learn and take part in the educational system. A high level of education is not only the precondition for the employability of people with disabilities, acquiring technical knowledge about how to use ATs in a self-determined and responsible way also increases the individual's ability to keep pace with new digital developments, their challenges, and risks. The results of our research further revealed that educational opportunities for people with disabilities are lower. The occupational groups dealing with ATs with regard to either IT and web accessibility or their use in the health care sector are also in need of training and further development of their skills. Therefore, new certification programs for specialization in ATs would be very welcome.

Finally, yet importantly, the field of employment shows that technical devices can play a very important role. However, the inclusion of people with disabilities into the labor market remains highly challenging and often fails due to negative attitudinal barriers, which prevent a fair judgment of the disabled people's working capacity. In order to improve this situation, on the one hand, more legislative steps are required using the UNCRPD ("reasonable accommodation") as a starting point. On the other hand, companies should be much better supported by public authorities with regard to specific requirements, needs, and practical hints, but also in terms of supporting ATs to make the employment process of people with disabilities as easy as possible.

With regard to future approaches for the "socio-technical development" of ATs, which we proposed in this article, further research, but also political steps, are crucial to establishing the connection between ATs, their users, and the social surrounding (professionals and services). The following areas are, from our perspective, the key to shaping the future of ATs in a responsible manner:

- There is still only very little knowledge about the concrete use of ATs in specific societal contexts. An interesting and relevant field of further research would be the use of ATs in the workplace, were the most barriers toward people with disabilities could be observed. Thus, it would be essential to widen the knowledge base about how and what ATs are used here. Furthermore, the existing shortcomings and the concrete factors contributing to the gap between the low employment rate and the manifold opportunities of technical support should be elaborated. It would also be of high interest to compare the use of ATs by people with disabilities with the technical support dedicated to and developed for an aging workforce, as this could reveal mutual learning potentials.

- With regard to future research on technical development and social integration, there should be an increased focus on cognitive disabilities. Currently, there are only very few solutions in place that are, on top/above that very rarely publicly financed since they are not considered medical devices. Mainstream digital technologies play an important here. However, regarding the mentioned complexities of the digital world, research and political action should focus on emerging challenges.

Finally, the socio-technical understanding of ATs that was proposed in this article should be further elaborated in a conceptual manner. It seems very promising to connect established approaches for the evaluation and assessment of technologies, such as TA or RRI, with ATs. This would pave 
the way for the use of both concepts and methods to tackle future socio-technical challenges in the field of ATs. TA approaches and methods such as Constructive Technology Assessment (CTA) [20] or Vision Assessment (VA) [21], could be used to further assess and evaluate existing technical strategies. In the case of RRI, this could imply the use of the normative concept of responsibility as guidance for technical design, development, and implementation in the field of ATs to help create "responsible innovations" in this field.

Author Contributions: Both authors were involved in data collection and analysis. L.N. wrote the first draft and M.M. complemented it. All authors have read and agreed to the published version of the manuscript.

Funding: This research was funded by the European Parliament Scientific Foresight Unit (STOA), Brussels.

Acknowledgments: We are extremely grateful to all experts for their availability for the interviews.

Conflicts of Interest: The authors declare no conflict of interest.

\section{Appendix A Interview Guidelines}

Table A1. Set I-Needs and Perceptions of ATs.

\begin{tabular}{|c|c|}
\hline Part & Questions \\
\hline 1. Introduction & $\begin{array}{l}\text { Description of position in the institution; area of responsibility; } \\
\text { professional/educational background; age; if applicable: type of } \\
\text { impairment/category of disability }\end{array}$ \\
\hline \multirow[t]{2}{*}{ 2. Basic views } & $\begin{array}{l}\text { 1. What is your definition/understanding of ATs? Do you know of other } \\
\text { definitions/understandings of ATs? }\end{array}$ \\
\hline & $\begin{array}{l}\text { 2. Could you describe your practical experience with ATs? How and } \\
\text { where do you use ATs in your organization? }\end{array}$ \\
\hline Practical experience with ATs & $\begin{array}{l}\text { - Which ATs do you use? } \\
\text { - Are there others you would like to use but have no access to? Why? } \\
\text { - } \quad \text { Whe there others you could use but do not use on purpose? Why? } \\
\text { using or want to use but cannot? Why? }\end{array}$ \\
\hline Overall goal of ATs & $\begin{array}{l}\text { From your experience: Which technical solutions (ATs) were specifically } \\
\text { helpful? Which technical solutions (ATs) failed in the past? Why? }\end{array}$ \\
\hline \multirow[t]{2}{*}{ Past } & $\begin{array}{l}\text { 4. Do you think that ATs should focus on improving the physical } / \text { mental } \\
\text { capacities of the disabled person or rather on making the environment } \\
\text { friendlier and removing obstacles? }\end{array}$ \\
\hline & $\begin{array}{l}\text { 5. What kind of ATs do you think will be needed in the future? What kind } \\
\text { of ATs might be developed in the future? What kind of technical } \\
\text { development is needed? Which are the ones you would like to see being } \\
\text { developed in the future? }\end{array}$ \\
\hline Future & $\begin{array}{l}\text { - What is important for your future vision of ATs to come true? } \\
\text { - Which technical fields are crucial for future developments? } \\
\text { - What kind of ATs do you see on the market in the future? (BCI, } \\
\text { drones, robots, autonomous cars, ... ) } \\
\text { - How can the use of ATs be improved in the future? (Are new } \\
\text { legislation/regulations needed? Do the existing ones need revision?) }\end{array}$ \\
\hline
\end{tabular}


Table A1. Cont.

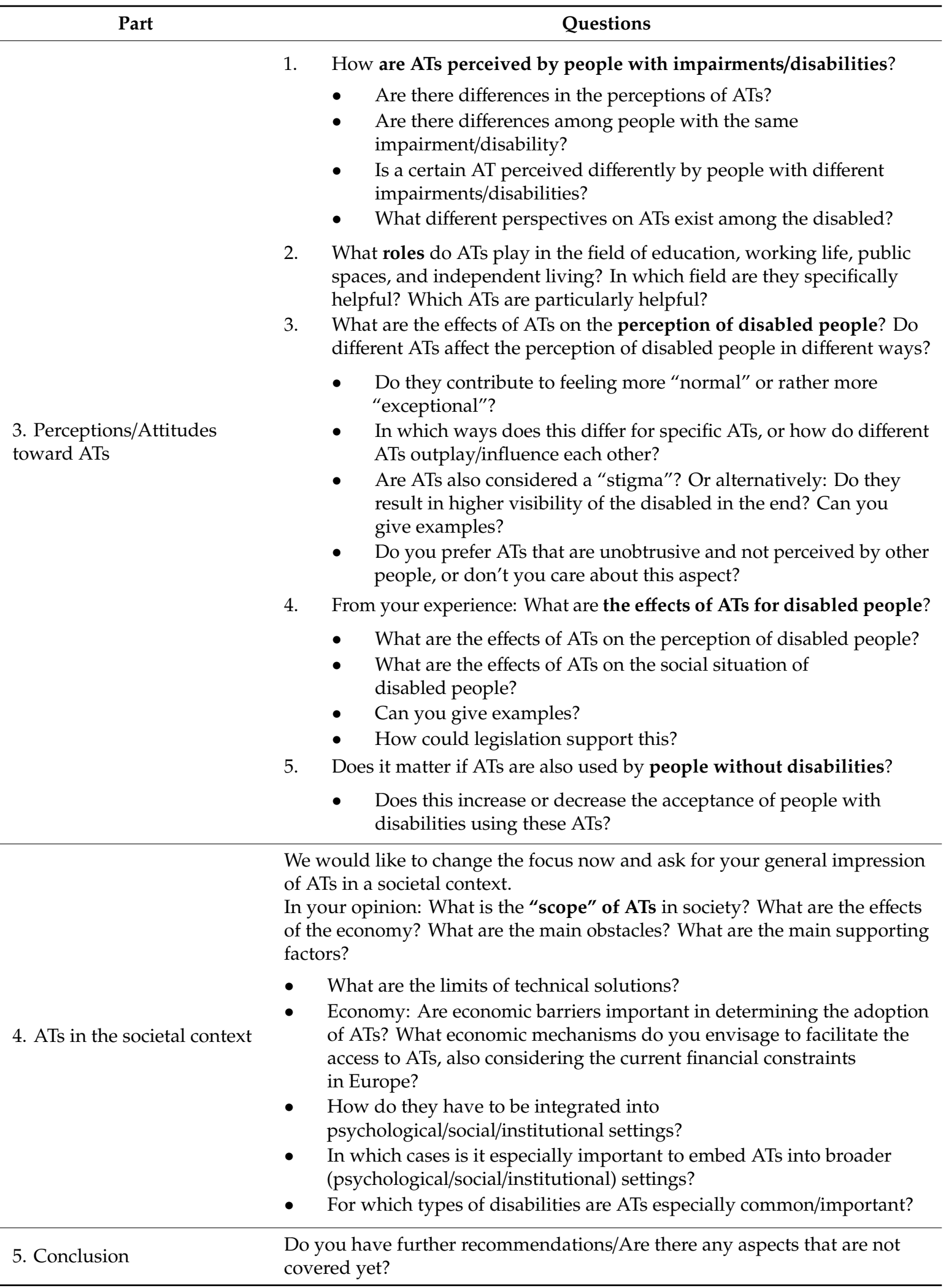


Table A2. Set II-Complementary Measures by the Public Sector.

\begin{tabular}{|c|c|}
\hline Part & Question \\
\hline 1. Warm-up/Introduction & $\begin{array}{l}\text { Description of position in the institution; area of responsibility; how long in the job; age; } \\
\text { category of disability; professional background/education }\end{array}$ \\
\hline \multirow[t]{3}{*}{$\begin{array}{l}\text { 2. Practical experience with } \\
\text { current regulations }\end{array}$} & $\begin{array}{l}\text { 1. Could you describe your/your organization's practical experience with the } \\
\text { current regulations on ATs for people with disabilities? }\end{array}$ \\
\hline & $\begin{array}{l}\text { 2. Can you give examples of current political instruments to support ATs in } \\
\text { employment/education/public spaces/independent living? }\end{array}$ \\
\hline & $\begin{array}{l}\text { - Is there, e.g., some form of public financial support? } \\
\text { - In your opinion, what could be improved? Further quotas? Improving the } \\
\text { national implementation of European guidelines? }\end{array}$ \\
\hline Negative examples & $\begin{array}{l}\text { Which regulations for ATs failed in the past in employment/education/public } \\
\text { spaces/independent living? In what sense did they fail? }\end{array}$ \\
\hline \multirow{6}{*}{$\begin{array}{l}\text { 3. Political measures for ATs in } \\
\text { employment, education, public } \\
\text { spaces, independent living }\end{array}$} & $\begin{array}{l}\text { 1. Why is it important to have regulations on ATs? Which measures are adequate? } \\
\text { Are you aware of European/national differences? Are there countries in which } \\
\text { regulations for ATs are currently missing? }\end{array}$ \\
\hline & $\begin{array}{l}\text { What is your opinion on the UNCRPD? } \\
\text { Article 4: General obligations: To undertake or promote research and } \\
\text { development of, and to promote the availability and use of new technologies, } \\
\text { including information and communications technologies, mobility aids, } \\
\text { devices and assistive technologies, suitable for persons with disabilities, } \\
\text { giving priority to technologies at an affordable cost; } \\
\text { And: } \\
\text { To provide accessible information to persons with disabilities about mobility } \\
\text { aids, devices and assistive technologies, including new technologies, as well } \\
\text { as other forms of assistance, support services and facilities; }\end{array}$ \\
\hline & $\begin{array}{l}\text { To support in the fields of personal mobility, habilitation \& rehabilitation, function as a } \\
\text { support for voting; to provide access to ATs with the aim of international cooperation. }\end{array}$ \\
\hline & $\begin{array}{l}\text { - What do you think about the aims for ATs in the UN convention? } \\
\text { - } \quad \text { Does the Convention have an effect on the situation of disabled people in Europe? } \\
\text { - } \quad \text { How could the Convention affect the situation of disabled people in Europe? } \\
\text { - How could the Convention affect the situation of ATs for disabled people in Europe? }\end{array}$ \\
\hline & $\begin{array}{l}\text { 3. Are political measures needed for fields that develop ATs? If yes, which ones (e.g., } \\
\text { regulations, incentives (e.g., de-taxation), and funding programs)? Should there be } \\
\text { also "bans" on ATs that should not be developed? For what reasons? }\end{array}$ \\
\hline & $\begin{array}{l}\text { - Which political measures in the field of employment/education/public } \\
\text { spaces/independent living are needed in the future for ATs? Why? } \\
\text { - Which political measures were specifically helpful for ATs? } \\
\text { - Who has benefited from these measures? Has one group of disabled people } \\
\text { benefited more than others? } \\
\text { Are there specific measures needed for specific ATs? If yes, can you } \\
\text { give examples? }\end{array}$ \\
\hline \multirow{4}{*}{ 4. ATs in the political context } & $\begin{array}{l}\text { We would like to change the focus now and ask for your general impression of ATs in the } \\
\text { current political context. } \\
\text { From your experience: }\end{array}$ \\
\hline & $\begin{array}{l}\text { 1. If you think of regulating ATs, what are the main obstacles of generating and } \\
\text { implementing regulations? Why? }\end{array}$ \\
\hline & $\begin{array}{l}\text { 2. Can the use of ATs be improved in the future in Europe and nationally? If yes, how } \\
\text { can the use of ATs be improved in the future in Europe and nationally (by } \\
\text { regulations)? }\end{array}$ \\
\hline & $\begin{array}{l}\text { Do you know about "best case"/“worst-case" examples? (Selected countries: Germany, } \\
\text { Hungary, Portugal, Sweden) }\end{array}$ \\
\hline 5. Conclusion & Do you have further recommendations/Are there any aspects that are not covered yet? \\
\hline
\end{tabular}




\section{Appendix B LIST of Experts Interviewed}

\begin{tabular}{|c|c|c|}
\hline & Date of Interview & Organization \\
\hline \multirow{5}{*}{ SET I } & 06 June 2016 & EBU_European Blind Union \\
\hline & 17 June 2016 & ILUNION \\
\hline & 20 June 2016 & Autism-Europe \\
\hline & 23 June 2016 & EASPD—European Association of Service Providers for Persons with Disabilities \\
\hline & 31 August 2016 (via Email) & EUD—European Union of the Deaf \\
\hline \multirow{9}{*}{ SET II } & 08 June 2016 & EBU_European Blind Union \\
\hline & 20 June 2016 & Autism-Europe \\
\hline & 20 June 2016 & Physician \\
\hline & 28 June 2016 & Researcher \\
\hline & 06 July 2016 & ISSA-International Social Security Association/Europe \\
\hline & 07 July 2016 & MedTech Europe \\
\hline & 31 August 2016 (via Email) & EUD—European Union of the Deaf \\
\hline & 11 July 2016 & ILO-International Labour Organization (specialized agency of the UN) \\
\hline & 19 July 2016 & WHOWorld Health Organization \\
\hline
\end{tabular}

\section{Appendix C Analytical Strategy}

Table A3. Set I-Needs and Perceptions of ATs.

\begin{tabular}{cl}
\hline \multicolumn{1}{c}{ Subcategory } & \multicolumn{1}{c}{ Codes } \\
\hline \multirow{2}{*}{ Societal fields * } & $\begin{array}{l}\text { Independent living * } \\
\text { Education * } \\
\text { Employment }\end{array}$ \\
\hline \multirow{2}{*}{ Research and innovation } & $\begin{array}{l}\text { Participatory development and universal design } \\
\text { Emerging technologies }\end{array}$ \\
\hline \multirow{2}{*}{ Challenges } & Accessibility \\
& Acceptance and awareness \\
\hline & $*$ referred to in this article.
\end{tabular}

Table A4. Set II-Complementary Measures by the Public Sector.

\begin{tabular}{cc}
\hline Subcategory & Codes \\
\hline Legislation & $\begin{array}{c}\text { UN Convention } \\
\text { European Accessibility Act }\end{array}$ \\
\hline Political measures in societal fields * & $\begin{array}{c}\text { ATs under the medical device regulation } \\
\text { International perspectives on the regulation of ATs }\end{array}$ \\
\hline Economic framework & $\begin{array}{c}\text { Independent living * } \\
\text { Education * }\end{array}$ \\
\hline Technologment * & \\
\hline
\end{tabular}

\section{References}

1. WHO. Priority Assistive Products List; WHO: Geneva, Switzerland, 2016.

2. Maia, M.; Nierling, L. "We don't want to be the exception and thanks to assistive technology we are getting relatively close to being there"-Assistive technologies for people with disabilities: Technologies, user needs and political challenges. In The Politics and Situatedness of Emerging Technologies; Bowman, D., Dijkstra, A., Fautz, C., Guivant, J., Konrad, K., Shelley-Egan, C., Woll, S., Eds.; AKA Verlag: Berlin, Germany, 2017; pp. 131-150. 
3. World Health Organization. Improving Access to Assistive Technology Report by the Director-General; World Health Organization: Geneva, Switzerland, 2018; Volume 1, p. 6.

4. Norman, D. The Design Of Everyday Things; Basic Books: New York, NY, USA, 2013.

5. World Health Organization. Access to Medicines and Vaccines; World Health Organization: Geneva, Switzerland, 2019.

6. Gardner, C.A.; Acharya, T.; Yach, D. Technological and Social Innovation: A Unifying New Paradigm for Global Health. Health Aff. 2007, 26, 1052-1061. [CrossRef] [PubMed]

7. Nierling, L.; Maia, M.; Čas, J.; Capari, L.; Krieger-Lamina, J.; Wolbring, G.; Bratan, T.; Kukk, P.; Hennen, L.; Mordini, E. Assistive Technologies for People with Disabilities. Part III: Perspectives on Assistive Technologies Study; European Parliament: Brussels, Belgium, 2018.

8. Mayring, P. Qualitative Content Analysis. Forum Qual. Soz. Forum Qual. Soc. Res. 2000, 1, 159-176.

9. European Parliament and the Council of the European Union. Directive (EU) 2019/882 on the Accessibility Requirements for Products and Services; European Parliament: Brussels, Belgium, 2019; pp. 70-115.

10. Mordini, E.; Nierling, L.; Wolbring, G.; Maia, M.J.; Bratan, T.; Capari, L.; Čas, J.; Krieger-Lamina, J.; Kukk, P. Assistive Technologies for People with Disabilities. Part II: Current and Emerging Technologies; European Parliament: Brussels, Belgium, 2018.

11. United Nations. Convention on the Rights of Persons with Disabilities; United Nations: New York, NY, USA, 2016.

12. Mauldin, L. Made to Hear-Cochlear Implants and Raising Deaf Children; Palgrave: Basingstoke, UK, 2016.

13. Layton, N.; Steel, E. The Convergence and Mainstreaming of Integrated Home Technologies for People with Disability. Societies 2019, 9, 69. [CrossRef]

14. Weinberger, N.; Winkelmann, M.; Müller, K.; Ritterbusch, S.; Stiefelhagen, R. Public Participation in the Development Process of a Mobility Assistance System for Visually Impaired Pedestrians. Societies 2019, 9, 32. [CrossRef]

15. Kendall, E.; Oh, S.; Amsters, D.; Whitehead, M.; Hua, J.; Robinson, P.; Palipana, D.; Gall, A.; Cheung, M.; Potter, L.E.; et al. HabITec: A Sociotechnical Space for Promoting the Application of Technology to Rehabilitation. Societies 2019, 9, 74. [CrossRef]

16. Grunwald, A. Technology Assessment in Practice and Theory, 1st ed.; Routledge: London, UK, 2019.

17. von Schomberg, R.; Hankins, J. (Eds.) International Handbook on Responsible Innovation: A Global Resource; Edward Elgar Publishing: Cheltenham, UK, 2019.

18. Ienca, M.; Kressig, R.W.; Jotterand, F.; Elger, B. Proactive Ethical Design for Neuroengineering, Assistive and Rehabilitation Technologies: The Cybathlon Lesson. J. Neuroeng. Rehabil. 2017, 14, 115. [CrossRef] [PubMed]

19. Nierling, L.; Maia, M.; Bratan, T. Technological or social drivers for a transformation towards an inclusive society? The role of ATs for people with disabilities. In Gesellschaftliche Transformationen: Gegenstand oder Aufgabe der TA? Prill, M., Heyen, N., Lindner, R., Eds.; Sigma/Nomos: Baden-Baden, Germany, 2019; forthcoming.

20. Decker, M.; Weinberger, N.; Krings, B.-J.; Hirsch, J. Imagined technology futures in demand-oriented technology assessment. J. Responsible Innov. 2017, 4, 177-196. [CrossRef]

21. Lösch, A.; Grunwald, A.; Meister, M.; Schulz-Schaeffer, I. Introduction: Socio-Technical Futures Shaping the Present. In Socio-Technical Futures Shaping the Present; Lösch, A., Grunwald, A., Meister, M., Schulz-Schaeffer, I., Eds.; Springer: Berlin, Germany, 2019; pp. 1-14.

(C) 2020 by the authors. Licensee MDPI, Basel, Switzerland. This article is an open access article distributed under the terms and conditions of the Creative Commons Attribution (CC BY) license (http://creativecommons.org/licenses/by/4.0/). 